\title{
Maximization of integral outlet quantities of an axisymmetric synthetic jet actuator based on a loudspeaker
}

\author{
J. Kordík ${ }^{1, a}$ and Z. Trávníček ${ }^{1}$ \\ ${ }^{1}$ Institute of Thermomechanics, AS CR
}

\begin{abstract}
The goal of this paper is to find an optimal nozzle size of an axisymmetric synthetic jet actuator based on a loudspeaker. The desirable maximized output quantities are: volumetric flow, momentum flux, and kinetic energy flux. To evaluate these quantities velocity profiles were measured using a hot-wire probe at the actuator nozzle exit. Six different nozzle diameters and three supplied real power levels were tested to find the maxima of the quantities. The actuator operated always at resonance during experiments. It was found out that the momentum flux and the kinetic energy flux reach distinguishable local maxima at particular diameters of the nozzle. Besides, the maxima of the particular quantities do not coincide and the best nozzle size slightly increases with the supplied real power to the actuator.
\end{abstract}

\section{Introduction}

Synthetic jets (SJs), or zero-net-mass-flux jets, are fluid flows that are generated by fluid pulsations and are formed in a free space behind a nozzle. The fluid is pushed and pulled through the nozzle, whose inner part exits into a cavity. The source of the pulsations is an oscillating diaphragm that bounds one side of the cavity. The nozzle is the only inlet/outlet in/from the cavity, therefore time mean mass flux through the nozzle is zero. The momentum flux along the nozzle axis is, however, non-zero, therefore the flow continues ahead downstream from the nozzle exit and forms similar flow structures as a continuous jet.

Since the end of the last century, the topic of synthetic jets has been intensively investigated [1,2] and many useful applications of SJs have been developed. The applications of SJs have been found especially in boundary-layer separation control [3-10], jet vectoring [11-16], heat transfer enhancement [17-22], and mixing [23-25]. A variant of the SJ, namely a non-zero-net-mass-flux jet (or hybrid SJ), has been investigated more recently [26-28,21,29-31].

It is a known fact that the most convenient operating condition from the energetic point of view is a resonance (if we consider the synthetic jet actuators based on elastic diaphragms e.g. based on a loudspeaker or a piezoceramic membrane etc.). Therefore, many authors concentrated their efforts on location and prediction of the SJ actuator resonances (see e.g. [32-44]). Having a SJ actuator operating at a resonance frequency, there are still a lot of ways how to enhance its exploitable outlet quantities such as volumetric flow, momentum or kinetic energy fluxes. This will be the topic of this work. Particularly, this paper investigates the axisymmetric SJ actuator based on a loudspeaker and working at the first resonance. Under these conditions the goal is to find such a nozzle diameter of the SJ actuator

a e-mail: kordik@it.cas.cz to achieve a) the highest volumetric flow, b) the highest momentum flux, and c) the highest kinetic energy flux. The optimization is made here experimentally with the following constrictions: the actuator works with an incompressible fluid, the diaphragm (loudspeaker) properties and the nozzle diameter to length ratio are constant, and the diaphragm excitation is sinusoidal (harmonic).

\section{Observed Parameters}

First of all we define a characteristic velocity of the SJ, which is used in the present auxiliary experiments (including measurements of velocity resonance curves):

$$
U_{0}=\frac{1}{T S_{\mathrm{N}}} \int_{0}^{T_{\mathrm{E}}} \int_{S_{\mathrm{N}}} u \mathrm{~d} S \mathrm{~d} t,
$$

where $S_{\mathrm{N}}$ is the nozzle exit cross-sectional area $(\mathrm{d} S$ is the differential element of $S_{\mathrm{N}}$ ), $u$ denotes the velocity component aligned with the nozzle axis, $T_{\mathrm{E}}$ is the extrusion stroke duration time, $T$ is the actuation period, and the areaaveraged velocity $\frac{1}{S_{\mathrm{N}}} \int_{S_{\mathrm{N}}} u \mathrm{~d} S$ has the origin at $t=0(t$ is time).

Now, we can define the observed quantities, whose maxima are desirable. The definitions of the quantities follow in this order: the time-average volumetric flow $\left(Q_{0}\right)$, momentum flux $\left(M_{0}\right)$, and kinetic energy flux $\left(E_{0}\right)$ :

$$
\begin{gathered}
Q_{0}=\frac{1}{T} \int_{0}^{T_{\mathrm{E}}} \int_{S_{\mathrm{N}}} u \mathrm{~d} S \mathrm{~d} t=U_{0} S_{\mathrm{N}}, \\
M_{0}=\frac{1}{T} \int_{0}^{T_{\mathrm{E}}} \int_{S_{\mathrm{N}}} \rho u^{2} \mathrm{~d} S \mathrm{~d} t, \\
E_{0}=\frac{1}{T} \int_{0}^{T_{\mathrm{E}}} \int_{S_{\mathrm{N}}} \frac{\rho u^{3}}{2} \mathrm{~d} S \mathrm{~d} t,
\end{gathered}
$$


where $\rho$ is the working fluid density.

Note, that the interval $\left(0, T_{\mathrm{E}}\right)$ can be a bit different for each quantity $Q_{0}, M_{0}$, and $E_{0}$. Generally, the interval represents a time spans where the surface integrals from Eqs. $(2,3,4)$ are greater or equal to zero.

\section{Experimental Setup and Methods}

\subsection{The Synthetic Jet Actuators}

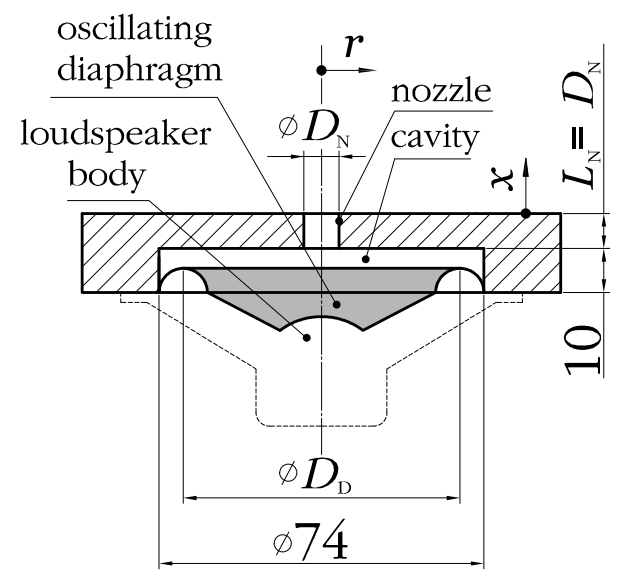

Fig. 1. Schema of the current actuator.

Figure 1 shows the schematic view of the tested SJA that operates at standard room conditions (temperature $20-$ $25{ }^{\circ} \mathrm{C}$ and barometric pressure $970-990 \mathrm{hPa}$ ) with air as the working fluid. The present actuator is based on a Aurasound NS3-193-8A loudspeaker, whose diaphragm generates the fluid oscillations in the nozzle.

During all experiments, the loudspeaker of the actuator was supplied by a harmonic electric current generated by Agilent 33220A function generator and gained in Pioneer A-209R amplifier. The experiments were performed with the following set of replaceable nozzles: $D_{\mathrm{N}}=6,8,12$, 15,20 , and $30 \mathrm{~mm}$. The length of all nozzles was always $L_{\mathrm{N}}=D_{\mathrm{N}}$.

Each nozzle was attached to the actuator body and the velocities were measured by a hot-wire probe at the nozzle outer exit. The measurements were performed at actuator velocity resonance and for three input power levels: $P_{\mathrm{e}}=$ $0.05,0.24$, and $1.18 \mathrm{~W}$. The desirable quantities $Q_{0}, M_{0}$, and $E_{0}$ were evaluated numerically from the velocity measurements using corresponding Eqs. $(2,3,4)$.

\subsection{Data Acquisition and Hardware Setup}

As was mentioned above the quantities $Q_{0}, M_{0}$, and $E_{0}$ will be investigated at the actuator velocity resonance. To locate the velocity resonances auxiliary experiments were performed primarily. These experiments included the measurements of velocity resonance curves. The curves are represented by the characteristic velocity, $U_{0}$, as function of the actuating frequency, $f$, and were acquired at constant power input into the actuator.

The velocities $U_{0}$ for the resonance curves were evaluated from a velocity waveform obtained at the centre of the nozzle ( $r=0$ and $x=0$, for the coordinate system see figure 1). The MiniCTA 54T30 DANTEC hot-wire anemometer with a single wire probe 55P16 and the NI-PCI 6023E data acquisition device were used for this measurement. The hot-wire signal was sampled with a sampling frequency of $f \cdot 64$ and the number of samples was 16384 . The temperature of the working fluid (air) was measured using a fast-response Pt100 sensor (PT100-SMD0805) at the same time as the velocity samples. The measured temperature was used for the temperature correction of the hot-wire data. To evaluate and check the constant power input into the actuator, the supplied electric current and voltage were acquired concurrently with velocity and temperature samples.

After the identification of the velocity resonance frequencies (for each combination of the nozzle diameter and input power level), the velocity profiles were measured at the resonances along nozzle diameter at the distance of $x=0.3 \mathrm{~mm}$. The velocity profiles were acquired at 14 discrete positions on the nozzle diameter. The same experimental equipment and hardware setup as during auxiliary experiments was used.

For all measurements the hot-wire probe was calibrated in the velocity range of $0.2-53 \mathrm{~m} / \mathrm{s}$. The maximum relative uncertainty of a single velocity sample was below $5 \%$ for velocities in range of $0.4-53 \mathrm{~m} / \mathrm{s}$. For very small velocities in the range of $0.2-0.4 \mathrm{~m} / \mathrm{s}$ the uncertainty was $14.2 \%$. A more detailed description of the anemometer settings, probe calibration method, and uncertainty evaluation is available in [42].

\section{Experimental Results}

\subsection{Auxiliary Experiments}

The measured resonance curves for identification of particular resonance frequencies are shown in figure 2 . The set of curves in figure 2 was acquired at constant power input into the actuator: $P_{\mathrm{e}}=0.24 \mathrm{~W}$ and for the full set of replaceable nozzle diameters. Other power levels were tested, as well, but the locations of the resonance frequencies for the same nozzles did not change substantially.

Figure 2 reveals the fact that the resonance frequency gets higher with the increasing nozzle diameter. Moreover, we can notice that the resonance curve for the smallest diameter $\left(D_{\mathrm{N}}=6 \mathrm{~mm}\right)$ is quite flat and the resonance peak is hardly identifiable. This is caused by a strong damping having an origin in local losses at cavity/nozzle or nozzle/ambiance transitions.

The experimentally located velocity resonance frequencies, $f_{\text {res }}$, are listed in table 1 ; they can be, however, evaluated easily theoretically, as well. The appropriate formula can be found e.g. in $[44,31]$ : 


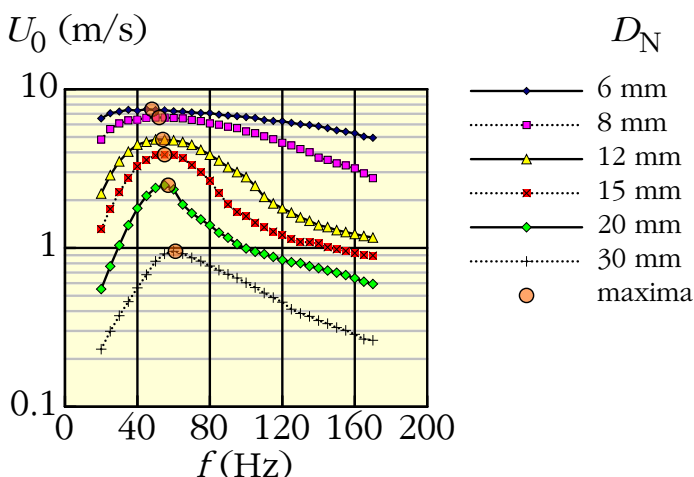

Fig. 2. Resonance curves and their maxima acquired at $P_{\mathrm{e}}=$ $0.24 W$.

Table 1. The parameters of experiments, found resonances.

\begin{tabular}{cccc}
\hline$D_{\mathrm{N}}(\mathrm{mm})$ & \multicolumn{2}{c}{$f_{\text {res }}(\mathrm{Hz})$} & $P_{\mathrm{e}}(\mathrm{W})$ \\
& Experiment & Theory & \\
\hline 6 & 48 & 47.0 & \\
8 & 52 & 50.3 & \\
12 & 54 & 54.4 & $0.05,0.24,1.18$ \\
15 & 55 & 56.3 & \\
20 & 57 & 58.4 & \\
30 & 61 & 60.9 & \\
\hline
\end{tabular}

$$
\begin{aligned}
& f_{\text {res }}=\frac{1}{2 \pi} \sqrt{\frac{K_{\mathrm{D}}}{m_{\mathrm{D}}+D_{\mathrm{D}}^{4} / D_{\mathrm{N}}^{4} m_{\mathrm{N}}}}, \text { where }: \\
& m_{\mathrm{N}}=\frac{\rho \pi D_{\mathrm{N}}^{2}}{4}\left(L_{\mathrm{N}}+0.85 D_{\mathrm{N}}\right),
\end{aligned}
$$

and where $K_{\mathrm{D}}=704 \mathrm{~N} / \mathrm{m}$ is the diaphragm spring constant, $m_{\mathrm{D}}=3.9 \mathrm{~g}$ is its mass, and $D_{\mathrm{D}}=61.8 \mathrm{~mm}$ is the diaphragm effective diameter (the values of these parameters were identified in [43]). The fluid mass moving in the nozzle and its vicinity is assigned $m_{\mathrm{N}}$. The evaluation of $m_{\mathrm{N}}$ suggested in Eq. (5) is taken from [45]. Comparing the experimental and theoretical results in table 1 we can state that there is an acceptable agreement.

\subsection{Main Experiments and Discussion}

The next results were obtained only at resonance frequencies summarized in table 1. Figure 3 shows the results evaluated for the volumetric flows, $Q_{0}$. The flows, $Q_{0}$, are drawn here as functions of the ratio $D_{\mathrm{N}} / D_{\mathrm{D}}$. A monotonous character of all curves in figure 3 implies the following: to achieve the highest value of $Q_{0}$ the optimal nozzle diameter should be large as possible. By other words, the diameter for maximal volumetric flows from the SJA probably does not exist for the current configurations. This phenomenon can be explained from the theory of linear damped harmonic

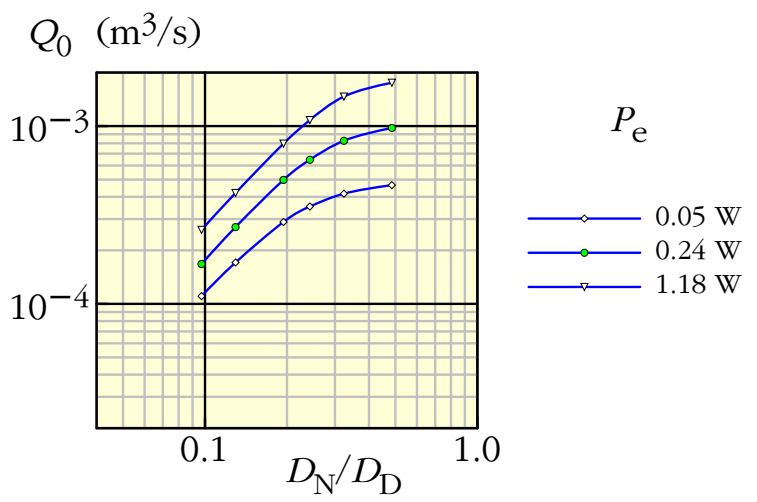

Fig. 3. Volumetric flows.

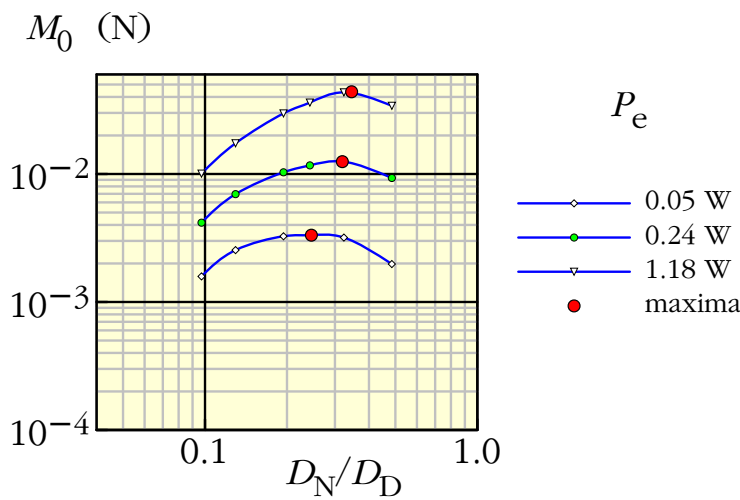

Fig. 4. Momentum flux.

$$
E_{0}(\mathrm{~W})
$$

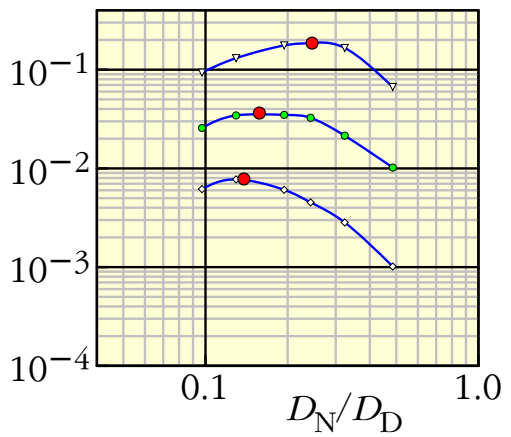

$P_{\mathrm{e}}$

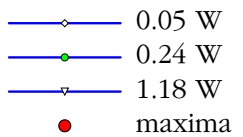

Fig. 5. Kinetic energy flux.

oscillator. An increasing damping of the forced oscillator always decreases its displacements and velocities in the whole frequency range (and especially at resonance frequency). The narrower the nozzle is, the higher damping is imposed onto the oscillating diaphragm. Therefore, due to the incompressibility conditions the highest volumetric flows can be achieved with the largest nozzles (or without any nozzle and the actuator body, but in this case no SJ would be produced, see [46]).

Results obtained for the momentum flux can be seen in figure 4. Clear maxima were found for each input power level at the ratio of $D_{\mathrm{N}} / D_{\mathrm{D}}=0.25-0.35$. Moreover, we 
can notice that for a maximum momentum flux, the optimal nozzle diameter slightly increases with increasing input power, $P_{\mathrm{e}}$.

Very similar results as for the momentum flux were found for the kinetic energy flux - see figure 5. The local maxima were found for each input power level at the ratio of $D_{\mathrm{N}} / D_{\mathrm{D}}=0.14-0.25$. Therefore, we can conclude that smaller nozzle diameters are necessary to operate the actuator with the maximal kinetic energy flux than with the maximal momentum flux.

It is worth to note here that actuators working at resonance and having the optimal nozzle diameters with respect to the kinetic energy flux work with maximal energetic efficiency defined by $[47,31]$.

\section{Conclusion}

A synthetic jet actuator based on a loudspeaker was tested with various nozzles and input powers at the first resonance frequency. The nozzle diameter to length ratio was constant $\left(D_{\mathrm{N}} / L_{\mathrm{N}} \approx 1\right)$ and operating medium was air at incompressible conditions. Outlet velocity profiles were measured by hot-wire probe at the actuator nozzle exit. The values of the volumetric flow, momentum flux, and kinetic energy flux were evaluated from the measured velocity profiles.

The maximal volumetric flow was found for the largest tested nozzle diameter. The volumetric flow as function of the nozzle diameter appeared to be monotonic and had no local maximum. On the other hand, momentum and kinetic energy fluxes had their local maxima at particular nozzle diameters. An optimal geometry of the actuator, represented by a ratio of the nozzle diameter to the diaphragm diameter, slightly depended on the actuator input power. In both cases (momentum and kinetic energy fluxes) the best nozzle diameter slightly increased with the increasing power input and was larger for momentum flux than for the kinetic energy flux.

\section{Acknowledgement}

We gratefully acknowledge the support of the Grant Agency CR (project number 14-08888S) and the institutional support RVO:61388998.

\section{References}

1. B.L. Smith, A. Glezer, Physics of Fluids 10, 2281 (1998)

2. J.E. Cater, J. Soria, Journal of Fluid Mechanics 472, 167 (2002)

3. G. Hong, Sensor Actuat. A-Phys. 132, 607 (2006)

4. J. Dandois, E. Garnier, P. Sagaut, J. Fluid Mech. 574, 25 (2007)

5. D. You, P. Moin, J. Fluid Struct. 24, 1349 (2008)

6. S.G. Mallinson, J.A. Reizes, R. Hillier, Flow Turbulence and Combustion 66, 1 (2001)

7. M. Amitay, A. Glezer, International Journal of Heat and Fluid Flow 23, 690 (2002)
8. R. Rathnasingham, K.S. Breuer, Journal of Fluid Mechanics 495, 209 (2003)

9. S. Lardeau, M.A. Leschziner, Journal of Fluid Mechanics 683, 172 (2011)

10. C. Bernardini, M. Carnevale, M. Manna, F. Martelli, D. Simoni, P. Zunino, Journal of Thermal Science 21, 404 (2012)

11. B.L. Smith, A. Glezer, Journal of Fluid Mechanics 458 , $1(2002)$

12. Z.B. Luo, Z.X. Xia, Modern Physics Letters B 19, 1619 (2005)

13. Z.B. Luo, Z.X. Xia, Y.G. Xie, Chinese Journal of Aeronautics 20, 193 (2007)

14. Z.X. Xia, Z.B. Luo, Applied Mathematics and Mechanics 28, 907 (2007)

15. D.A. Tamburello, M. Amitay, International Journal of Heat and Fluid Flow 29, 967 (2008)

16. M. Ben Chiekh, M. Ferchichi, J.C. Béra, Experiments in Fluids 53, 1797 (2012)

17. M.B. Gillespie, M.S. thesis, Georgia Institute of Technology (1998)

18. Z. Trávníček, V. Tesař, International Journal of Heat and Mass Transfer 46, 3291 (2003)

19. M.B. Gillespie, W.Z. Black, C. Rinehart, A. Glezer, Journal of Heat Transfer 128, 990 (2006)

20. M. Arik, Applied Thermal Engineering 27, 1483 (2007)

21. Z. Trávníček, V. Tesař, J. Kordík, Journal of Visualization 11, 221 (2008)

22. M. Chaudhari, B. Puranik, A. Agrawal, International Journal of Heat and Mass Transfer 53, 1057 (2010)

23. H. Wang, S. Menon, AIAA Journal 39, 2308 (2001)

24. M. Al-Atabi, Journal of Fluids Engineering 133, 094503 (2011)

25. Q. Xia, S. Zhong, International Journal of Heat and Fluid Flow 37, 64 (2012)

26. Z. Trávníček, A.I. Fedorchenko, A.B. Wang, Sensors and Actuators A: Physical 120, 232 (2005)

27. Z. Trávníček, T. Vít, V. Tesař, Physics of Fluids 18, 081701 (2006)

28. V. Tesař, Sensors and Actuators A 138, 394 (2007)

29. J. Kordík, Z. Trávníček, Journal of Fluids Engineering 135, 101101 (2013)

30. Z. Trávníček, T. Vít, International Journal of Heat and Mass Transfer 85, 473 (2015)

31. J. Kordík, Z. Trávníček, M. Pavelka, Experimental Thermal and Fluid Science 69, 119 (2015)

32. Q. Gallas, M.S. thesis, University of Florida, Gainesville (2002)

33. Q. Gallas, J. Mathew, A. Kaysap, R. Holman, T. Nishida, B. Carroll, M. Sheplak, L. Cattafesta, Lumped element modeling of piezoelectric-driven synthetic jet actuators, in 40th AIAA Aerospace Sciences Meeting $\mathcal{F}$ Exhibit (AIAA Paper 2002-0125, Reno, 2002)

34. Q. Gallas, R. Holman, T. Nishida, B. Carroll, M. Sheplak, L. Cattafesta, AIAA Journal 41, 240 (2003)

35. Q. Gallas, M. Sheplak, L. Cattafesta, Final report for NAG-1-03031, University of Florida, Department of Mechanical and Aerospace Engineering, Gainesville (2005) 
36. Q. Gallas, R. Holman, R. Raju, R. Mittal, M. Sheplak, L. Cattafesta, Low dimensional modeling of zero-net mass flux actuators, in 2nd AIAA Flow Control Conference (AIAA Paper 2004-2413, Portland, 2004)

37. Q. Gallas, $\mathrm{PhD}$. thesis, University of Florida, Gainesville (2005)

38. B.H. Kim, D.R. Williams, S. Emo, M. Acharya, AIAA Journal 43, 314 (2005)

39. H. Tang, S. Zhong, Lumped element modelling of synthetic jet actuators, in The 3rd AIAA Flow Control Conference (AIAA Paper 2006-3696, San Francisco, 2006)

40. H. Tang, S. Zhong, M. Jabbal, L. Garcillan, F. Guo, N. Wood, C. Warsop, Flow, Turbulence and Combustion 78, 309 (2007)

41. H. Tang, S. Zhong, Aerospace Science and Technology 13, 331 (2009)

42. J. Kordík, Synthetic and Hybrid Synthetic Jet Actutators - Theoretical and Experimental Analysis (LAP LAMBERT Academic Publishing, 2013), ISBN 978-3659-32910-4

43. J. Kordík, Z. Trávníček, AIAA Journal 51, 2862 (2013)

44. J. Kordík, Z. Broučková, T. Vít, M. Pavelka, Z. Trávníček, Experiments in Fluids 55, 1757 (2014)

45. L.E. Kinsler, A.R. Frey, A.B. Coppens, J.V. Sanders, Fundamentals of acoustics, 4th edn. (John Wiley \& Sons, Inc. New York, 2000)

46. R. Holman, Y. Utturkar, R. Mittal, B.L. Smith, L. Cattafesta, AIAA Journal 43, 2110 (2005)

47. Z. Broučková, Z. Trávníček, Journal of Visualization (2015) 